Canadian

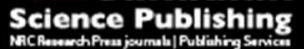

Canadian Journal of Civil Engineering Revue canadienne de génie civil

\title{
A Guided Evaluation of the Impact of R\&D Partnerships on University, Industry, and Government
}

\begin{tabular}{|r|l|}
\hline Journal: & Canadian Journal of Civil Engineering \\
\hline Manuscript ID & cjce-2016-0381.R1 \\
\hline Manuscript Type: & Article \\
\hline Date Submitted by the Author: & 12 -Dec-2016 \\
\hline Complete List of Authors: & $\begin{array}{l}\text { Daoud, Ahmed; University of Alberta, Civil and Environmental Engineering } \\
\text { Tsehayae, Abraham Assefa; University of Alberta, Department of Civil and } \\
\text { Environmental Engineering } \\
\text { Robinson Fayek, Aminah; University of Alberta, Dept. of Civil and } \\
\text { Environmental Engineering }\end{array}$ \\
\hline Keyword: & $\begin{array}{l}\text { construction industry, construction companies, research and development, } \\
\text { strategic planning, engineering }\end{array}$ \\
\hline &
\end{tabular}


A Guided Evaluation of the Impact of R\&D Partnerships on University, Industry, and Government

Ahmed Osama Daoud, Abraham Assefa Tsehayae, Ph.D., and Aminah Robinson Fayek, Ph.D., P.Eng.

MSc Candidate and Graduate Research Assistant, Dept. of Civil and Environmental Engineering, Univ. of Alberta, 1-043 Markin/CNRL Natural Resources Engineering Facility, Edmonton, AB, T6G 2W2, Canada. E-mail: aodaoud@ualberta.ca

Postdoctoral fellow, Dept. of Civil and Environmental Engineering, Univ. of Alberta, 7381 Donadeo Innovation Center for Engineering, Edmonton, AB, T6G 1H9, Canada. Email: tsehayae@ualberta.ca

NSERC Industrial Research Chair in Strategic Construction Modeling and Delivery, Ledcor Professor in Construction Engineering, Professor, Dept. of Civil and Environmental Engineering, Univ. of Alberta, 7-203 Donadeo Innovation Centre for Engineering, Edmonton, AB, T6G 1H9, Canada (corresponding author). E-mail: aminah.robinson@ualberta.ca 


\begin{abstract}
Research and development (R\&D) partnerships involve investigative activities that may result in new discoveries and innovations that are critical for the technological advancement of the engineering domain. While demonstrating the value of these partnerships is essential for encouraging investment, the engineering domain lacks a formal evaluation framework. In this paper, a methodology and framework for evaluating R\&D partnerships is introduced. The effectiveness of the developed framework is tested using a case study that focuses on the role of the university within the Natural Sciences and Engineering Research Council of Canada (NSERC) Industrial Research Chair (IRC) program. Using correlation analysis, the activities and investment areas that lead to the desired outcomes for the university research are identified. By using the developed framework over time and applying it to different research programs and industries, key activities and investment areas can be established and improved R\&D policies and implementation plans developed.
\end{abstract}

Keywords: Construction industry, construction companies, engineering, research and development, strategic planning. 


\section{Introduction and Background}

According to Hagedoorn et al. (2000), R\&D partnerships can be defined as "cooperative arrangements engaging universities, industries, and government agencies and laboratories in various combinations to pool resources in pursuit of a shared R\&D objective.” Universities, industries, and government agencies are considered to be the main drivers of R\&D partnership programs. Such R\&D partnerships lead to different forms of knowledge and technology transfer, which encourages innovation and facilitates the development of strong collaborative networks (Bekkers and Freitas 2008). Universities and industries are commonly linked through cooperation on R\&D projects (Lee and Win 2004). There are many advantages of collaboration for both universities and industries; for example, R\&D partnerships afford universities the opportunity to develop and patent new products and procedures, advance their research capacity, and apply their research within industrial contexts. On the other hand, industry groups experience benefits including new opportunities to hire highly qualified personnel (e.g., graduate students); gain access to the facilities and research centers of the partnering university; recruit university researchers as consultants on industry issues; and improve the quality and cost efficiency of their tools and practices.

The government plays an important role in enhancing and supporting R\&D partnerships by investing funds through different federal agencies (Hampson et al. 2014). For example, the Government of Canada supports R\&D partnerships in the construction domain through different organizations such as the National Research Council (NRC), Canada Foundation for Innovation (CFI), and Natural Sciences and Engineering Research Council of Canada (NSERC) (Fayek et al. 2014). In the US, construction R\&D partnerships are supported through federal agencies such as the National Science Foundation (NSF), Department of 
Energy (DOE), Environmental Protection Energy (EPA), Department of Transportation (DOT), and Department of Commerce (DOC) (Slaughter et al. 2014).

However, industrial support for R\&D partnerships in Canada has been noticeably decreasing over the past few years (Council of Canadian Academies (CCA) 2013; Statistics Canada 2015); this decline has negatively affected collaboration between universities and industries, as well as the overall performance of industrial R\&D programs (CCA 2013). To remedy this issue, the demand for R\&D programs must be increased, especially across large Canadian organizations, and new investments need to be attracted (CCA 2013). The CCA (2013) has recommended that Canadian organizations increase investments in R\&D projects to ensure their future growth and maintain their competitive advantage and profitability.

Moreover, there are several barriers to establishing effective collaborative relationships between universities and industries, which can be grouped under orientation- and transactionrelated barriers (Bruneel et al. 2010). Orientation-related barriers arise due to the misalignment of attitudes and perceptions related to research between universities and industries. In contrast, transaction-related barriers stem from conflicts over intellectual property and administrative miscommunications. These two types of barriers can be reduced by three mechanisms: (1) establishing a history of effective collaboration; (2) expanding the breadth of interaction channels between universities and industries; and (3) increasing the level of trust between both parties (Bruneel et al. 2010).

In order to improve the current status of industrial $R \& D$ partnerships, it is important that their value be demonstrated to all invested parties. Ensuring the mutual value of R\&D partnerships is a critical component in maintaining collaborative relationships, attracting investment in industrial $\mathrm{R} \& \mathrm{D}$ projects, mitigating relationship barriers, and enhancing 
communication. The different components of R\&D partnerships (i.e., inputs, outputs, and outcomes) can be assessed using an evaluation framework, where inputs represent resources, outputs represent activities, and outcomes represent intended results. In particular, the "logic model" stands out as one of the most effective tools among the approaches used for assessing R\&D partnerships (Fielden et al. 2007). Logic models have been widely used in developing, implementing, and evaluating the performance of programs in various contexts, such as health research programs, and can easily demonstrate the qualitative relations among the different components of programs. However, logic models have not yet been applied and tested in the construction research domain (Daoud et al. 2016).

The purpose of this paper is to provide the engineering research domain with an evaluation framework that consists of a logic model and evaluation plan, in order to define and assess the outcomes and impacts of R\&D partnerships for the invested parties (i.e., universities, industry groups, and government agencies). The proposed evaluation framework works by assessing the qualitative relationships among the different components of R\&D partnerships. The evaluation plan helps to determine the degree to which the outcomes and impacts of the partnership have been achieved from the perspectives of each party so that their inputs (i.e., resources) and outputs (i.e., activities) can be improved for better future outcomes.

This paper begins with a literature review of the logic model. Next, the methodology used to develop an evaluation framework for $R \& D$ partnerships is presented. Then, results from a case study evaluation of a collaborative research partnership under the NSERC IRC program are discussed, and the validated logic model resulting from the analysis is presented. Finally, our conclusions and recommendations for future research are presented.

\section{Literature Review}


Numerous logic models have been developed over the past 30 years, and they are utilized in the planning, implementation, and evaluation of programs in many different contexts (Fielden et al. 2007). The logic model tells the story of a partnership through investigating its components, which include resources (inputs); activities (outputs); and short-, medium-, and long-term outcomes. For example, logic models are used in developing and implementing partnerships within the health-research community (Fielden et al. 2007); they have also been utilized in applications related to the performance management of national drug control programs in the US (Millar et al. 2001). In Alberta, logic models are used extensively to evaluate and maintain the efficiency of the primary health care system (Primary Health Care Branch 2013). Additionally, logic models are used by government bodies in Canada, such as the "Treasury Board of Canada Secretariat", to assess program performance and manage expenditures (Treasury Board of Canada Secretariat 2010). Logic models are also widely used in the grant application processes for various funded research programs, where they are used to evaluate and monitor these programs and ensure their performance efficiency (Fielden et al. 2007).

Several studies have investigated the benefits of using logic models in program implementation and evaluation processes. Dwyer and Makin (1997) suggest that logic models offer the following advantages: 1) they allow for programs to be visualized and made understandable to stakeholders; 2) they help to illustrate the interrelationships between the program inputs and results; and 3) they allow for program planning and evaluation processes to be integrated. Millar et al. (2001) also notes that logic models are help tools for accomplishing the following tasks: 1) identifying external factors that may act as obstacles to achieving desired end results; 2) reaching consensus among program participants in regards to 
the program inputs and outputs needed to reach particular outcomes; 3) improving the communication between stakeholders; and 4) providing a means for selecting alternative approaches to help achieve program goals.

Despite the advantages offered by logic models in program evaluation, they have yet to be applied within the construction research domain (Daoud et al. 2016). However, before a framework for evaluating R\&D partnerships can be developed, there are two main issues that must be addressed. First, there is a lack of clear definitions regarding the components of R\&D partnerships (i.e., inputs, outputs, outcomes, and impacts). Second, the literature lacks a comprehensive study evaluating relationships among the components of R\&D partnerships (i.e., inputs, outputs, and outcomes) in order to determine which inputs highly relate to outputs, and which outputs highly relate to outcomes.

Based on the aforementioned advantages of $R \& D$ partnerships, their challenges and barriers, and the absence of an R\&D evaluation framework, a logic model-based approach has been found to be suitable for use within the construction research domain. An evaluation framework for assessing the different components (i.e., inputs, outputs, and outcomes) of R\&D partnerships can be constructed by integrating a logic model with an evaluation plan (Taylor-Powell et al. 1998; American Evaluation Association (AEA) 2015). This approach will enable parties involved in different $R \& D$ partnerships to identify expected outcomes that were not achieved and improve results by adjusting the inputs and outputs. As discussed above, logic models can enhance communication and help collaborating parties to reach a common agreement regarding their investments and activities required to fulfill the intended results of the partnership. These advantages will help in aligning the attitudes of collaborating parties and in mitigating barriers to effective collaborative relationships. 


\section{Development of an Evaluation Framework for R\&D Partnerships}

The research methodology used to develop the evaluation framework consists of five steps: (1) compiling criteria for each of the three components of $R \& D$ partnerships (i.e., inputs, outputs, and outcomes); (2) developing metrics and scales to measure and evaluate the different criteria; (3) designing questionnaires to collect data for each metric; (4) administering the questionnaires to respondents; and (5) analyzing the responses. These five steps are investigated in detail in the following sections.

\section{Criteria for Representing the Role of the Collaborating Parties in the R\&D Partnership}

Figure 1, Figure 2, and Figure 3 show the components of the logic model (i.e., inputs, outputs, and outcomes) representing the roles of university, industry, and government, respectively. Each component is represented by a list of criteria that were identified by analyzing existing literature on logic models created for R\&D partnerships (AEA 2015; Behrens et al. 2015; Jordan 2015; University of Wisconsin-Extension (UWEX) 2003; McCawley 2001; Fielden et al. 2007; Remtulla et al. 2014; Tremblay et al. 2010; NRC 2009; Goss Gilroy Inc. (GG) 2006; NSERC 2009; Research Councils UK (RCUK) et al. 2014). In addition, other criteria have been added (e.g., trust in industrial partners working on R\&D projects, teamwork effectiveness in R\&D collaborations, communicating R\&D progress and results through the university research team's website), which are in line with the definition of inputs, outputs, and outcomes for R\&D partnerships.

[Please insert Figures 1, 2, and 3]

Inputs represent the resources invested in an $R \& D$ partnership. For example, inputs related to the university include human resources, equipment and facilities, time, and research accomplishments (Behrens et al 2015). Outputs are the activities done through the partnership. 
For example, the activities carried out by the university include doing research in collaborative teams, publishing papers, and introducing presentations at conferences (Behrens et al 2015). Outcomes represent the intended results of the activities and the changes expected by the partnership participants. For example, short-term outcomes represent advancements in knowledge, skills, attitudes, motivation, and awareness (UWEX 2003); these outcomes include the results of the program that occur directly after the completion of outputs. In contrast, medium-term outcomes represent changes and developments in behaviors, practices, decisions, actions, strategies, and policies (UWEX 2003); these outcomes include results of the program that occur after the fulfillment of short-term outcomes. Long-term outcomes (i.e., impacts) represent positive impacts on social, economic, political, scientific, and environmental conditions (UWEX 2003); these outcomes account for the results of the program created by the fulfillment of medium-term outcomes.

Implementation of the Proposed Evaluation Framework for R\&D Partnerships: Case Study of Construction R\&D Partnership

The proposed logic model for R\&D partnerships was further adapted to evaluate a collaborative research partnership in the construction domain that exists under the NSERC IRC program. This case study assesses the aforementioned R\&D partnership for its capacity to meet the needs and expectations of the following parties that are reached and impacted by the partnership: the university, which is represented by the chairholder of an NSERC IRC grant and the research team members (i.e., postdoctoral fellows, graduate students, and support staff); the construction industry, which is represented by a number of partner organizations directly involved in the NSERC IRC; and the government, which is represented by Canadian federal funding agency NSERC. 


\section{Development of Metrics and Scales for Criteria in the R\&D Logic Model}

The criteria used to measure the three components of R\&D partnerships (i.e., inputs, outputs, and outcomes) were further detailed using quantitative and qualitative measurement metrics. Several studies were reviewed to support the development of the metrics used to evaluate the relevant criteria and to create the scales used to measure the metrics (Jyoti et al. 2006; Samsonowa et al. 2009; Chiesa et al. 2008; Choi and Ko 2010; Ojanen and Vuola 2003; Sawang 2011; Agostino et al. 2012; Elbarkouky et al. 2014; Hanel and St-Pierre 2006; Holi et al. 2008; NSERC 2009; Paine 2003; Park et al. 2013; Schwartz et al. 2011; University of Victoria 2011; Weisbrod and Weisbrod 1997; RCUK et al. 2014). In this study, numerical scales (i.e., numerical values and percentages) were used to measure different quantitative metrics in the proposed model (Omar and Fayek 2014), and Likert scales (i.e., rating scales), defined by Vagias (2006), were used to measure the qualitative metrics (Rea and Parker 1997). In addition, other rating scales were developed to suit the context of the metrics. For example, the criterion "linking scientific theories with practical applications" listed in Figure 1 in the short-term outcomes for the university was evaluated using the qualitative metric "level of alignment of R\&D projects within the IRC with practical industry needs". This metric was measured using a five-point scale called "level of alignment": (1) not aligned at all, (2) slightly aligned, (3) somewhat aligned, (4) very aligned, and (5) extremely aligned. Examples of criteria, corresponding metrics, and scales used for evaluating inputs and outputs, and outcomes for the university's role are shown in Table 1 and Table 2, respectively. Using the shown criteria, metrics, and scales, the evaluation of R\&D programs, such as the NSERC IRC and NSERC Collaborative Research and Development (CRD) Grants, can be carried out in a formal and systematic way. 
[Please insert Tables 1 and 2]

\section{Development of Questionnaires and Data Collection}

Three questionnaires were prepared to evaluate the relevant criteria for the R\&D partnership corresponding to each of the collaborating parties (i.e., the university, construction industry, and government agency). Each questionnaire has three sections, which focus on the evaluation of criteria for the inputs, outputs, and outcomes. The different criteria are assessed based on the evaluation of the respective metrics, which are framed into structured questions. Each metric is evaluated by either a single question or a series of defined questions. The questionnaires were designed using a prospective cohort approach, such that criteria are evaluated over a defined five-year time frame to monitor changes in each collaborating party's expected outcomes. This time frame was chosen due to the fact that the duration of each IRC term is five years, with the possibility of renewal.

The logic model and questionnaires were validated by consulting two experts: (1) an individual experienced in evaluating programs in the Alberta health research domain, and (2) a construction industry professional. The feedback from the program evaluation expert was helpful for the betterment of the overall logic model and the university questionnaire, and the feedback from the industry professional was useful in determining future directions for industry participation in this research.

\section{Analysis of the Evaluation Results for the University's Role in the NSERC IRC Partnership}

The developed university questionnaire was then piloted with all research team members of the NSERC IRC. The intent is to first apply the study on the university research team to 
investigate the appropriateness of the questionnaire and data analysis methods before collecting data from industrial partners and government. The aim of introducing the framework at this stage is to encourage other researchers engaged in R\&D collaborations to use it to evaluate their own programs and to develop it further for evaluating universityindustry-government $\mathrm{R} \& \mathrm{D}$ partnerships. Therefore, the statistical analysis carried out in this paper is focused on the evaluation of results from the university questionnaire. Accordingly, the subsequent analysis and key findings can be used to further extend the evaluation framework for the industry and government components by following the same steps applied on the university component presented in this paper. The questionnaires were distributed to the university research team members together with a consent form, and the questionnaires were collected upon completion. Using a total population sampling approach, the evaluation questionnaire was distributed to all 11 members of the research team, resulting in a $100 \%$ response rate. The respondents included the chairholder, one postdoctoral fellow, one technical writer, five doctoral students, and three master's students.

After the questionnaires were collected, an investigation of missing and completed responses was carried out. The respondent's level of experience in the research team played an important role in determining his/her response rate. Experience refers both to the length of time in which a respondent has been a member of the research team as well as the seniority of his/her position. For example, based on their experience, the chairholder and the postdoctoral fellow had the highest response rate among the research team members; on average, they answered $98 \%$ of the questionnaire. On the other hand, senior doctoral students that have been members of the team for more than one year answered, on average, $73 \%$ of the questionnaire. The responses from one respondent (i.e., a junior master's student) were eliminated from the 
study due to a high percentage of missing responses (i.e., 91\% of missing responses), which may lead to distortion of the analysis results.

However, in order to be able to proceed with other steps in inferential statistical analysis, the missing data had to be handled first. There are three main approaches for dealing with missing data: (1) listwise (casewise) deletion, (2) pairwise deletion, and (3) mean substitution. In the listwise case deletion approach, cases with missing data will only be dropped if a small number of the cases (i.e., respondents) overall have missing data (Marsh 1998; Schlomer et al. 2010). However, this approach was not applicable to the case study analysis, as all respondents had some missing data. On the other hand, the pairwise deletion approach excludes missing data from the analysis and instead, only uses the existing data, which can produce very small, unequal data sets for each question and can lead to inaccurate results during correlation analysis (Marsh 1998; Schlomer et al. 2010). This approach was also not deemed to be appropriate due to the small data set involved in this study. To handle the missing data without distorting the small data set, the "mean substitution" approach was adopted. This method is widely used by researchers in social work (Saunders et al. 2006), as it is a relatively easy technique to apply and does not require complicated calculations (Mundfrom and Whitcomb 1998). Instead, the mean substitution approach uses the mean of the total sample for a specific question or variable to fill in the missing values (Kent 2015).

Inferential statistical analysis (i.e., correlation analysis) was used to determine the correlation between the criteria for inputs and outputs, as well as the correlation between the criteria for outputs and outcomes. In order to carry out the analysis at the criteria level, the questionnaire responses had to be aggregated at the metric level to get a single score representing each criterion from the perspective of the respondent (Mazziotta and Pareto 
2013; Hudrliková 2013). Since different types of scales (i.e., numerical and Likert scales) were used to measure the metrics, each applicable response was "normalized" by assigning it a value ranging from 0 to 1 in order to enable aggregation (Mazziotta and Pareto 2013; Hudrliková 2013). In addition, the metric questions showing identical responses by all respondents were removed, as these values cannot be normalized. The process resulted in the removal of three outcome criteria, as the associated metrics had identical responses. Next, the normalized responses for the different metrics were aggregated. In the aggregation process, all metrics were assumed to have equal weights and to be independent of each other; arithmetic mean was used, as it is the most common and transparent method used in aggregating different variables (Salzman 2003). The result of the aggregation is represented by the "composite index", a score ranging from 0 to 1 , which is then divided over five-point rating scale in order to indicate the respondent's overall evaluation of each criterion: $0.00-0.20$ means "Poor", 0.21-0.40 means "Fair", 0.41-0.60 means "Good", 0.61-0.80 means "Very good", and 0.81-1.00 means "Excellent".

For example, the university outputs criterion "developing tools and solutions to problems through R\&D projects" was evaluated using three metrics, in which each metric is measured by one question (shown in Table 2). The first question asks about the frequency at which the tools and solutions developed by the university research team are successfully implemented by the industrial partners of the IRC; the second question asks about the number of new software applications developed by the university research team over the past five years; and the third question asks about the quality of the outcomes (e.g., new tools, solutions, and practices) produced by IRC projects. The responses for these three questions (respectively) by each of the ten respondents were as follows: $[4,2,4],[4,2,4],[3,1,4],[3,2,4],[3,2,4],[3$, 
$2,4],[3,2,4],[3,2,4],[2,2,4]$, and $[4,1,4]$. Each response was normalized on a scale of 0 to 1 using the minimum-maximum approach, with the exception of the responses to the third question, which were identical. Finally, the normalized responses were aggregated using the arithmetic mean approach in order to get a single score representing each respondent's evaluation of the criterion "developing tools and solutions to problems through R\&D projects"; the results were as follows: $1.00,1.00,0.25,0.75,0.75,0.75,0.75,0.75,0.50$, and 0.50. The mean of these responses was then calculated to derive the university research team's overall evaluation of this criterion, resulting in a score of 0.7 , which means "Very good" on the aforementioned five-point rating scale. Examples of inputs, outputs, and outcomes criteria and metrics for the university's role in the IRC are shown in Table 1 and Table 2, along with the composite indices and their corresponding interpretations.

In the next stage, the inferential statistical analysis was carried out in order to accomplish the following tasks: (1) to determine the interdependencies between the whole sets (i.e., inputs, outputs, and outcomes) that represent the partnership, and (2) to determine the relationships between the individual criteria that make up the sets. Accordingly, the canonical correlation analysis (CCA) and Spearman's correlation analysis (SCA) methods were chosen. The CCA is a multivariate statistical model that is used to determine whether two sets of variables are dependent on one another (Hair et al. 1998). The CCA is also able to identify the strength of the overall relationships that may exist between two sets; this value is represented by the canonical correlation coefficient $\left(R_{c}\right)$. In contrast, SCA is used to determine the strength of the relationships between each pair of variables, either within a set (e.g. inputs component set) or among sets (e.g. inputs and outputs sets) (Mukaka 2012); this value is represented by Spearman's correlation coefficient $\left(r_{s}\right)$. 


\section{Canonical Correlation Analysis (CCA)}

Canonical correlation analysis (CCA) was carried out to determine the interdependencies between the different sets included in the logic model (i.e., inputs and outputs, outputs and short-term outcomes, short-term outcomes and medium-term outcomes, and medium-term outcomes and long-term outcomes), and to investigate the strength of these relationships. However, CCA could not be applied to the complete sets due to a singularity error within the data set. A singularity error indicates that the correlation matrix between the two loaded sets is not positive definite (Rigdon 1997). A positive definite matrix has a determinant greater than 0.00001 (Field 2005). To overcome this obstacle, it is recommended that some of the sets' variables (i.e., criteria) be removed, specifically those that are not correlated at all (i.e., $r=0$ ) or those that have a high correlation (i.e., $r>0.9$ ) with the variables of the other set (Field 2005). In addition, it is critically important that variables within the same set with $r \geq 0.6$ be removed before applying CCA (Bros 2006). Accordingly, the singularity error problem was solved and a positive definite matrix was achieved.

All CCA tests were run using SPSS. The first test was applied to the inputs and outputs sets; the second test was applied to the outputs and short-term outcomes sets; the third test was applied to the short-term and medium-term outcomes sets; and the fourth test was applied to the medium-term and long-term outcomes sets. The CCA output for the first test is represented as three roots. The first root, which shows the strongest relationship between the two sets, was used for our analysis (Hair et al. 1998; Bros 2006). The first root takes into account the maximum amount of variance among the variables in the sets compared to the other roots; the second root takes into account the maximum amount of variance that is not accounted for by the first root, and so on (Hair et al. 1998). The significance of the 
relationship was reviewed using the null hypothesis $\left(H_{0}\right)$ that the two sets are independent of one another, which will be rejected at a significance level ( $p$ value) of $10 \%$ (i.e., $90 \%$ confidence interval). The proposed alternative hypothesis $\left(H_{I}\right)$ is that the two sets are dependent on one another. The $R_{c}$ value can be interpreted as the $r_{S}$ value to determine the strength of the relationship between the whole sets (Bros 2006). Accordingly, the following values of $R_{c}$ determine the strength of the relationship between the whole sets: 0.00 means no linear relationship; 0.01-0.30 means a weak relationship; 0.31-0.70 means a moderate relationship; 0.71-1.00 means a strong relationship; and 1.00 means a perfect linear relationship (Ratner 2009). When investigating the relationship between the inputs and outputs sets, it was found that $R_{c}=0.984$, which shows that there is a strong positive relationship between the two sets as a whole. The significance level is 0.031 , which is smaller than the adopted $p$ value in this study (i.e., 0.1). This means that there is sufficient evidence to reject $H_{0}$ (i.e., the outputs set is independent of the inputs set) in favor of $H_{l}$ (i.e., the outputs set is dependent on the inputs set).

Similarly, for the relationship between the outputs and short-term outcomes sets, it was found that $R_{C}=0.857$ at a significance level of 0.900 . In addition, for the relationship between the short-term outcomes and medium-term outcomes sets, it was found that $R_{c}=0.994$ at a significance level of 0.345 . Finally, for the relationship between the medium-term outcomes and long-term outcomes sets, it was found that $R_{c}=0.852$ at a significance level of 0.558 . For each of these three relationships, there is insufficient evidence to reject $H_{0}$ in favor of $H_{l}$, such that the short-term outcomes set is independent of the outputs set, the medium-term outcomes set is independent of the short-term outcomes set, and the long-term outcomes set is independent of the medium-term outcomes set. 


\section{Spearman's Correlation Analysis (SCA)}

Spearman's correlation analysis (SCA) was also adopted in the case study to investigate the relationships between the individual criteria, both within the same set and within different sets. SCA was used investigate the correlation between the following variables: inputs criteria with each other, inputs criteria with outputs criteria, outputs criteria with each other, outputs criteria with short-term outcomes criteria, short-term outcomes criteria with each other, shortterm outcomes criteria with medium-term outcomes criteria, medium-term outcomes criteria with each other, medium-term outcomes criteria with long-term outcomes criteria, and longterm outcomes criteria with each other. The Spearman's correlation coefficients $\left(r_{s}\right)$ were checked to identify relationships among the criteria in which the significance level ( $p$ value) was below $10 \%$. It was found that there is sufficient evidence to reject the null hypothesis $H_{0}$ (i.e., there is no correlation existing between the criteria) in favor of the alternative hypothesis $H_{l}$ (i.e., there is a correlation existing between some of the criteria). The following values of $r_{S}$ determine the strength of the relationship between the criteria: 0 means no linear relationship; $0.01-0.30$ means a weak relationship; $0.31-0.70$ means a moderate relationship; 0.71-1.00 means a strong relationship; and 1 means a perfect linear relationship (Ratner 2009). The type of the relationship depends on whether $r_{s}$, is positive or negative. A positive $r_{s}$ indicates a positive relationship, which means that whenever the value of a variable (i.e., criterion) increases, the value of the other variable increases. In contrast, a negative $r_{s}$ indicates a negative relationship, which means that whenever the value of a variable increases, the value of the other variable decreases.

The interrelationships (inter-correlations) within each set were investigated to determine the significant relationships among the criteria for each set. The results indicated that all sets 
have interrelationships among their criteria, with the exception of the medium-term outcomes set. Next, the criteria for each set (i.e., inputs, outputs, and outcomes) were refined, based on their significant correlations with the criteria in the subsequent layer. For example, for each of the eight inputs criteria, there is a statistically significant correlation with any one of the outputs criteria. This analysis was repeated to assess relationships between outputs and shortterm outcomes, short-term outcomes and medium-term outcomes, and medium-term outcomes and long-term outcomes, and the significantly correlated criteria were identified.

Finally, as shown in Figure 4, the criteria that were not correlated with any layers were removed and the different sets were simplified to show only dominant relationships. Figure 4 shows the final validated logic model representing the role of universities in $R \& D$ partnerships. The refined criteria in the validated logic model were then used to evaluate the university's role in the case study R\&D partnership. This final validated logic model illustrates the effect of each criterion in a set on the criteria of the subsequent layers. The validated model shows that a specific inputs criterion will lead to a specific outputs criterion, which will in turn result in specific outcomes criteria. Moreover, the model indicates the "chain of change" that connects the highly correlated criteria with each other, starting with inputs and ending with long-term outcomes. These chains of change can be used by university research teams to optimize inputs and outputs criteria for better results in cases when outcomes are not meeting expectations.

\section{[Please insert Figure 4]}

For example, in the chain of change shown in Figure 4, it was found that the inputs criterion "laboratories and facilities involved in R\&D projects" has a moderate positive relationship $\left(r_{s}=0.648\right)$ with the outputs criterion "participating in advisory committee 
meetings of the IRC". This outputs criterion has a strong positive relationship $\left(r_{s}=0.764\right)$ with the short-term outcomes criterion "increasing the knowledge of researchers". The composite indices of these inputs, outputs, and short-term outcomes criteria (respectively) are as follows: $0.32,0.67$, and 0.40 . These values suggest that the respondents' overall evaluations of the inputs criterion and the short-term outcomes criterion are fair, while the overall evaluation of the outputs criterion is very good. Therefore, if the knowledge of researchers has not increased to the extent expected by the university research team, the inputs and outputs criteria included in this chain must be modified to reach the desired outcome. More specifically, an increase in the laboratories and facilities involved in R\&D projects will lead to increased participation in advisory committee meetings for the IRC, and this will result in an increase in the knowledge of researchers. It is worth mentioning that the negatively correlated criteria shown in Figure 4 need to be further examined using a larger sample size (e.g., collecting data from different IRCs) in order to further valuate the reasons for these negative correlations.

\section{Conclusion and Future Research}

R\&D programs play an important role in the social and economic development of countries. Unfortunately, the level funding for Canadian R\&D projects invested by industry groups has been decreasing in recent years. Collaborative R\&D partnerships between universities, industry groups, and government agencies must be evaluated on a regular basis. It is important that the involved parties be able to understand how their invested resources (i.e., inputs) and activities (i.e., outputs) affect their targeted outcomes if they are to produce better end results. However, there is no formal framework for evaluating R\&D partnerships. In this paper, an evaluation framework was presented through a case study focused on 
assessing the role of university in the NSERC Industrial Research Chair. This evaluation framework will help in improving the future performance of Canadian R\&D partnerships.

This paper also presented an investigation of logic models, which are used in evaluating different types of programs in various domains such as health research. Following a literature review, different criteria representing the role of universities in $R \& D$ partnerships were compiled and discussed. Examples of different metrics and scales used in evaluating these criteria were also explored. In addition, this paper presented detailed statistical analysis of the evaluation results from a case study, leading to the validation of our logic model. By applying this logic model and evaluation framework to a variety of R\&D partnerships in different domains over time, key activities and areas for future R\&D investment can be identified based on the aggregated results, on which $\mathrm{R} \& \mathrm{D}$ policies and implementation plans can be developed.

In summary, this paper makes the following contributions to the scientific body of knowledge: 1) introducing the concept of the logic model to the engineering domain for the purpose of visualizing and evaluating different R\&D partnerships; 2) defining and representing the different components of R\&D partnerships (i.e., inputs, outputs, and outcomes); 3) compiling a list of evaluation criteria to represent the role of each collaborating party; 4) presenting a statistical approach to identify relationships between the partnership components; and 5) presenting a validated logic model to assess the university's role in R\&D partnerships, which can be used to evaluate and adjust university-specific inputs and outputs to achieve better outcomes.

Methods for assigning weights to evaluation metrics based on their relative importance to each criterion are being investigated. Also, other methods are being investigated, such as 
principal component analysis (PCA) and multi-criteria analysis (MCA), which are used in aggregating results from the metrics level to the criteria level. Future research will focus on evaluating the roles of the industry and government parties in R\&D partnerships. Finally, the developed framework presented in this paper will be used for continuous evaluation of the IRC research program so as to improve its performance by focusing on the invested resources and activities that affect the unfulfilled outcomes.

\section{References}

Agostino, D., Arena, M., Azzone, G., Molin, M.D., and Masella, C. 2012. Developing a performance measurement system for public research centres. International Journal of Business Science and Applied Management, 7(1): 1-18.

American Evaluation Association (AEA). 2015. Evaluating outcomes of publicly-funded research, technology and development programs: Recommendations for improving current practice. Research, Technology and Development Evaluation Topical Interest Group of the AEA Version 1.0, Washington, D.C.

Behrens, T., McGowen, L., and Gray, D. 2015. IUCRC Logic Model Update January 2015. Available from https://www.ncsu.edu/iucrc/Jan'15/Breakout\%201-3_Logic\%20Model_Behrens.pdf [accessed 10 May 2015].

Bekkers, R., and Freitas, I.M.B. 2008. Analysing knowledge transfer channels between universities and industry: To what degree do sectors also matter? Research Policy, 37(10): 1837-1853. 
Bros, S.M. 2006. Chapter 11: Canonical correlation. Available from http://www.sjsu.edu/people/shannon.../L11_Canonical_Correlation_S07.DOC [accessed 20 May 2016].

Bruneel, J., D'Este, P., and Salter, A. 2010. Investigating the factors that diminish the barriers to university-industry collaboration. Research Policy, 39(7): 858-868.

Chiesa, V., Frattini, F., Lazzarotti, V., Manzini, R., and Troja, I. 2008. An exploratory study on R\&D performance measurement practices: A survey of Italian R\&D intensive firms. Liuc Papers, 218(14): 1-36.

Choi, G., and Ko, S.S. 2010. An integrated metric for R\&D innovation measurement. In Proceedings of the International Conference on Technology Management for Global Economic Growth, Phuket, Tha., 18-22 July 2010. Institute of Electrical and Electronics Engineers, New York, NY. pp. 1-5.

Council of Canadian Academies (CCA). 2013. The state of industrial R\&D in Canada. The Expert Panel on Industrial R\&D in Canada, CCA, Ottawa, ON.

Daoud, A.O., Fayek, A. Robinson, and Fu, Z. 2016. Framework for assessing the impact of construction research and development on the construction industry and academia. In Proceedings of the Construction Research Congress, San Juan, Pri., 31 May-2 June 2016. American Society of Civil Engineers, Reston, VA, pp. 78-87.

Dwyer, J., and Makin, S. 1997. Using a program logic model that focuses on performance measurement to develop a program. Canadian Journal of Public Health, 88(6): 421-425.

Elbarkouky, M.M.G., Fayek, A. Robinson, and Gellatly, I.R. 2014. Evaluating construction team effectiveness: A fuzzy logic approach. International Journal of Architecture, Engineering and Construction, 3(4): 262-274 
Fayek, A. Robinson, Rankin, J.H., Razavi, S., and Thomas, R.J. 2014. Canada - innovation through collaboration. In R\&D Investment and Impact in the Global Construction Industry. Edited by K.D. Hampson, J.A. Kraatz, and A.X. Sanchez. Routledge, Oxon. pp. $64-65$.

Field, A. 2005. Factor analysis using SPSS. Available from http://users.sussex.ac.uk/ andyf/factor.pdf [accessed 21 May 2016].

Fielden, S.J., Rusch, M.L., Masinda, M.T., Sands, J., Frankish, J., and Evoy, B. 2007. Key considerations for logic model development in research partnerships: A Canadian case study. Evaluation and Program Planning, 30(2): 115-124. doi:10.1016/j.evalprogplan.2007.01.002.

Goss Gilroy Inc. (GG). 2006. Summative evaluation of the Industrial Research Chairs program. GG, Ottawa, ON.

Hair, J.F., Anderson, R.E., Tatham, R.L., and Black, W.C. 1998. Canonical correlation analysis. Available from http://www.mvstats.com/Downloads/Supplements/Canonical_Correlation_6e.pdf [accessed 23 May 2016].

Hagedoorn, J., Link, A.N., and Vonortas, N.S. 2000. Research partnerships. Research Policy, 29(4): 567-586. doi:10.1016/S0048-7333(99)00090-6.

Hampson, K.D., Kraatz, J.A., and Sanchez, A.X. 2014. The global construction industry and R\&D. In R\&D Investment and Impact in the Global Construction Industry. Edited by K.D. Hampson, J.A. Kraatz, A.X. Sanchez, Routledge, Oxon, pp. 16-17.

Hanel, P., and St-Pierre, M. 2006. Industry-university collaboration by Canadian manufacturing firms. The Journal of Technology Transfer, 31(4): 485-499. 
Holi, M., Wickramasinghe, R., and Leeuwen, M.V. 2008. Metrics for the evaluation of knowledge transfer activities at universities. Library House, Cambridge, UK.

Hudrliková, L. 2013. Composite indicators as a useful tool for international comparison: the Europe 2020 example. Prague economic papers, 22(4): 459-473

Jordan, G.B. 2015. Generic logic models for research, technology development, deployment, and innovation. Available from

https://higherlogicdownload.s3.amazonaws.com/EVAL/271cd2f8-8b7f-49ea-b925e6197743f402/UploadedImages/Community\%20Resources/RTD\%20generic\%20logic\%2 0models\%20Jordan\%20et\%20al\%20Feb\%202015\%203.ppt [accessed 11 December $2015]$.

Jyoti, Banwet, D.K., and Deshmukh, S.G. 2006. Balanced scorecard for performance evaluation of R\&D organization: A conceptual model. Journal of Scientific \& Industrial Research, 65(11): 879-886.

Kent, R.A. 2015. Chapter 2: Data preparation. In Analysing Quantitative Data: Variable-based and Case-based Approaches to Non-experimental Datasets. SAGE Publishing, Thousand Oaks, CA. pp. 47-56.

Lee, J., and Win, H.N. 2004. Technology transfer between university research centers and industry in Singapore. Technovation, 24(5): 433-442. doi:10.1016/S01664972(02)00101-3.

Mazziotta, M., and Pareto, A. 2013. Methods for constructing composite indices: One for all or all for one? Rivista Italiana di Economia Demografia e Statistica, 67(2): 67-80. 
Marsh, H.W. 1998. Pairwise deletion for missing data in structural equation models: Nonpositive definite matrices, parameter estimates, goodness of fit, and adjusted sample sizes. Structural Equation Modeling: A Multidisciplinary Journal, 5(1): 22-36.

McCawley, P.F. 2001. The logic model for program planning and evaluation. University of Idaho Extension, Moscow, ID.

Millar, A., Simeone, R.S., and Carnevale, J.T. 2001. Logic models: A systems tool for performance management. Evaluation and Program Planning, 24(1): 73-81.

Mukaka, M.M. 2012. Statistics corner: A guide to appropriate use of correlation coefficient in medical research. Malawi medical journal: the journal of Medical Association of Malawi, 24(3): 69-71.

Mundfrom, D.J., and Whitcomb, A. 1998. Imputing missing values: The effect on the accuracy of classification. American Educational Research Association, Washington, D.C.

National Research Council Canada (NRC). 2009. Portfolio evaluation of the NRC technology cluster initiatives. Planning and Performance Management Directorate, Strategy and Development Branch, Corporate Services, NRC, Ottawa, ON.

Natural Sciences and Engineering Research Council of Canada (NSERC). 2009. Investing in people - An action plan. Available from http://www.nserc-crsng.gc.ca/nserccrsng/Reports-Rapports/ActionPlan-PlanDaction_eng.asp [accessed 5 March 2016].

Ojanen, V., and Vuola, O. 2003. Categorizing the measures and evaluation methods of R\&D performance - A state-of-the-art review on R\&D performance analysis. Telecom Business Research Center Lappeenranta, Lappeenranta University of Technology, Lappeenranta, FI. 
Omar, M.N., and Fayek, A. Robinson. 2014. A Framework for identifying and measuring competencies and performance indicators for construction projects. In Proceedings of the Construction Research Congress, Atlanta, GA, May 19-21 2014. American Society of Civil Engineers, Reston, VA. pp. 2043-2052. doi:10.1061/9780784413517.208.

Paine, K.D. 2003. Guidelines for measuring trust in organizations. The Institute for Public Relations, Gainesville, FL.

Park, S.H., Han, S.H., and Chae, M.J. 2013. Quantitative performance measurement for construction R\&D projects. KSCE Journal of Civil Engineering, 17(4): 610-619.

Primary Health Care Branch, The. 2013. Primary health care evaluation framework. Alberta Health, Edmonton, AB.

Ratner, B. 2009. The correlation coefficient: Its values range between $+1 /-1$, or do they? Journal of Targeting, Measurement and Analysis for Marketing, 17(2): 139-142.

Rea, L.M., and Parker, R.A. 1997. Designing and conducting survey research: A comprehensive guide. Jossey-Bass Publishers, San Francisco, CA.

Remtulla, Z., Sun, C., Ball, L., Lolić, P., and Siegel, J. 2014. Proposal for evaluation of the Mitacs accelerate program. Available from

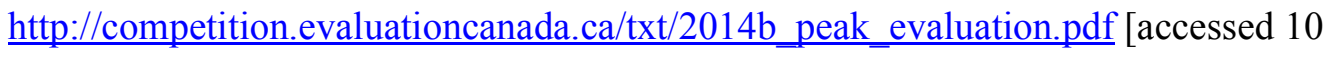
February 2016]

Research Councils UK (RCUK), the Researchfish Funders User Group, and RAND Europe. 2014. Research outcomes common question set. Available from http://www.rcuk.ac.uk/documents/documents/researchoutcomescommonquestionset-pdf/ [accessed 25 April 2016]. 
Rigdon, E.E. 1997. Not positive definite matrices--Causes and cures. Available from http://www.gsu.edu/ mkteer/npdmatri.html [accessed 10 May 2016].

Salzman, J. 2003. Methodological choices encountered in the construction of composite indices of economic and social well-being. Center for the Study of Living Standards, Ottawa, ON.

Samsonowa, T., Buxmann, P., and Gerteis, W. 2009. Defining KPI sets for industrial research organizations - A performance measurement approach. International Journal of Innovation Management, 13(2): 157-176.

Saunders, J.A., Morrow-Howell, N., Spitznagel, E., Doré, P., Proctor, E.K., and Pescarino, R. 2006. Imputing missing data: A comparison of methods for social work researchers. Social Work Research, 30(1): 19-31.

Sawang, S. 2011. Key performance indicators for innovation implementation: Perception vs. actual usage. Asia Pacific Management Review, 16(1): 23-29.

Schlomer, G.L., Bauman, S., and Card, N.A. 2010. Best practices for missing data management in counseling psychology. Journal of Counseling Psychology, 57(1): 1-10.

Schwartz, L., Miller, R., Plummer, D., and Fusfeld, A.R. 2011. Measuring the effectiveness of R\&D. Industrial Research Institute, Arlington, VA

Slaughter, S., Thomas, D., and Chapman, R. 2014. USA - characteristics, impacts and future directions. In R\&D Investment and Impact in the Global Construction Industry. Edited by K.D. Hampson, J.A. Kraatz, and A.X. Sanchez, Routledge, Oxon, United Kingdom, pp. $265-267$.

Statistics Canada. 2015. Industrial research and development: Intentions. Catalogue No. 88202-X, Ministry of Industry, Ottawa, ON. 
Taylor-Powell, E., Rosing, B., and Geran, J. 1998. Evaluating collaboratives: Reaching the potential. Program Development and Evaluation, Cooperative Extension, University of Wisconsin-Extension, Madison, WI.

Treasury Board of Canada Secretariat. 2010. Supporting effective evaluations: A guide to developing performance measurement strategies. Available from http://www.tbs-

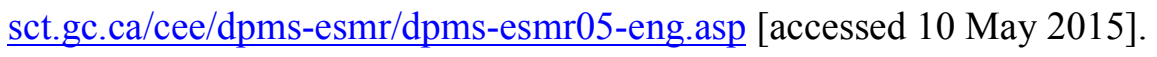

Tremblay, G., Zohar, S., Bravo, J., Potsepp, P., and Barker, M. 2010. The Canada Foundation for Innovation's outcome measurement study: A pioneering approach to research evaluation. Research Evaluation, 19(5): 333-345.

University of Victoria (UVic). 2011. Description of the ten core competencies. Co-operative Education Program and Career Services, UVic, Victoria, BC.

University of Wisconsin-Extension (UWEX). 2003. Welcome to enhancing program performance with logic models. UWEX, Madison, WI.

Vagias, W.M. 2006. Likert-type scale response anchors. Clemson International Institute for Tourism and Research Development, Department of Parks, Recreation and Tourism Management, Clemson University, Clemson, SC.

Weisbrod, G., and Weisbrod, B. 1997. Measuring economic impacts of projects and programs. Economic Development Research Group, Boston, MA. 
Table 1. Examples of Inputs and Outputs Criteria and Corresponding Metrics for the University Party

\begin{tabular}{|c|c|c|c|c|c|}
\hline Component & Criterion & Metric & Scale & $\begin{array}{l}\text { Mean (Standard } \\
\text { Deviation) for } \\
\text { each Criterion }\end{array}$ & $\begin{array}{l}\text { Interpretation } \\
\text { of Composite } \\
\text { Index }\end{array}$ \\
\hline \multirow[t]{4}{*}{ Inputs } & $\begin{array}{l}\text { Previous R\&D } \\
\text { achievements }\end{array}$ & $\begin{array}{l}\text { - Number of R\&D projects with industry } \\
\text { participants of the IRC completed on time and } \\
\text { on budget over the past } 5 \text { years }\end{array}$ & Numerical values & \multirow[t]{2}{*}{$0.43(0.23)$} & \multirow[t]{2}{*}{ Good } \\
\hline & & $\begin{array}{l}\text { - Total number of R\&D projects with industry } \\
\text { participants of the IRC over the past } 5 \text { years }\end{array}$ & Numerical values & & \\
\hline & $\begin{array}{l}\text { Laboratories and } \\
\text { facilities involved } \\
\text { in } R \& D \text { projects }\end{array}$ & $\begin{array}{l}\text { - Number of laboratories and/ or research spaces } \\
\text { involved in R\&D projects within the IRC }\end{array}$ & Numerical values & \multirow[t]{2}{*}{$0.32(0.21)$} & \multirow[t]{2}{*}{ Fair } \\
\hline & & $\begin{array}{l}\text {-Quality of laboratories and/ or research spaces } \\
\text { used in R\&D projects within the IRC }\end{array}$ & $\begin{array}{l}\text { 1-Poor, 2-Fair, 3-Good, } \\
\text { 4-Very good, 5- } \\
\text { Excellent }\end{array}$ & & \\
\hline \multirow[t]{3}{*}{ Outputs } & $\begin{array}{l}\text { Doing research in } \\
\text { collaborative } R \& D \\
\text { teams }\end{array}$ & $\begin{array}{l}\text { - Frequency of doing research in collaboration } \\
\text { with industrial partners of the IRC }\end{array}$ & $\begin{array}{l}\text { 1-Never, 2-Rarely, } \\
\text { 3-Sometimes, 4-Often, } \\
\text { 5-Usually }\end{array}$ & \multirow[t]{3}{*}{$0.52(0.14)$} & \multirow[t]{3}{*}{ Good } \\
\hline & & $\begin{array}{l}\text { - Time spent in years by graduate students (i.e., } \\
\text { doctorate and master's students) to complete } \\
\text { their degrees within the IRC }\end{array}$ & Numerical values & & \\
\hline & & $\begin{array}{l}\text { - Number of graduate students posted at industrial } \\
\text { partners' organization and/or job sites within the } \\
\text { IRC over the past } 5 \text { years }\end{array}$ & Numerical values & & \\
\hline
\end{tabular}




\begin{tabular}{|c|c|c|c|c|c|}
\hline Component & Criterion & Metric & Scale & $\begin{array}{l}\text { Mean (Standard } \\
\text { Deviation) for } \\
\text { each Criterion }\end{array}$ & $\begin{array}{l}\text { Interpretation } \\
\text { of Composite } \\
\text { Index }\end{array}$ \\
\hline & & $\begin{array}{l}\text { - Number of basic, applied, and basic and applied } \\
\text { R\&D projects carried out within the IRC over } \\
\text { the past } 5 \text { years }\end{array}$ & Numerical values & \multirow{5}{*}{$0.70(0.23)$} & \multirow{5}{*}{ Very good } \\
\hline & & $\begin{array}{l}\text { - Level of satisfaction with the collaboration on } \\
\text { R\&D projects within the IRC }\end{array}$ & $\begin{array}{l}\text { 1-Very dissatisfied, } \\
\text { 2-Dissatisfied, 3-Unsure, } \\
\text { 4-Satisfied, 5-Very } \\
\text { satisfied }\end{array}$ & & \\
\hline & \multirow[t]{3}{*}{$\begin{array}{l}\text { Developing tools } \\
\text { and solutions to } \\
\text { problems through } \\
\text { R\&D projects }\end{array}$} & $\begin{array}{l}\text { - Frequency of implementing tools and solutions } \\
\text { developed through R\&D projects by the } \\
\text { industrial partners of the IRC }\end{array}$ & $\begin{array}{l}\text { 1-Never, 2-Rarely, } \\
\text { 3-Sometimes, 4-Often, } \\
\text { 5-Usually }\end{array}$ & & \\
\hline & & $\begin{array}{l}\text { - Number of software applications developed } \\
\text { through R\&D projects within the IRC over the } \\
\text { past } 5 \text { years }\end{array}$ & Numerical values & & \\
\hline & & $\begin{array}{l}\text { - Level of quality of R\&D projects results within } \\
\text { the IRC }\end{array}$ & $\begin{array}{l}\text { 1-Poor, 2-Fair, 3-Good, } \\
\text { 4-Very good, 5- } \\
\text { Excellent }\end{array}$ & & \\
\hline
\end{tabular}

Note: The last column shows the descriptive statistics of the normalized composite indices of each criterion, on a scale of 0 to 1 , which were determined based on the respondents' evaluations of the metrics for the criteria. 
Table 2. Examples of Outcomes Criteria and Corresponding Metrics for the University Party

\begin{tabular}{|c|c|c|c|c|c|c|}
\hline Component & $\begin{array}{c}\text { Class of } \\
\text { Outcomes }\end{array}$ & Outcome Criterion & Metric & Scale & $\begin{array}{c}\text { Mean } \\
\text { (Standard } \\
\text { Deviation) for } \\
\text { each Criterion }\end{array}$ & $\begin{array}{c}\text { Interpretation } \\
\text { of Composite } \\
\text { Index }\end{array}$ \\
\hline \multirow{4}{*}{ Outcomes } & \multirow[t]{2}{*}{$\begin{array}{c}\text { Short-term } \\
\text { outcomes }\end{array}$} & $\begin{array}{l}\text { Graduating highly } \\
\text { experienced } \\
\text { personnel }\end{array}$ & $\begin{array}{l}\text { - Level of increase in the } \\
\text { experience of the university } \\
\text { research team by participating } \\
\text { in R\&D projects within the IRC }\end{array}$ & $\begin{array}{l}\text { 1-Very low, 2-Low. } \\
\text { 3-Medium, } \\
\text { 4-High, 5-Very high }\end{array}$ & $0.55(0.28)$ & Good \\
\hline & & $\begin{array}{l}\text { Linking scientific } \\
\text { theories with } \\
\text { practical applications }\end{array}$ & $\begin{array}{l}\text { - Level of alignment of R\&D } \\
\text { projects within the IRC with } \\
\text { practical industry needs }\end{array}$ & $\begin{array}{l}\text { 1-Not aligned at all, } \\
\text { 2-Slightly aligned, } \\
\text { 3-Somewhat } \\
\text { aligned, } \\
\text { 4-Very aligned, } \\
\text { 5-Extremely aligned }\end{array}$ & $0.55(0.28)$ & Good \\
\hline & \multirow[t]{2}{*}{$\begin{array}{c}\text { Medium-term } \\
\text { outcomes }\end{array}$} & $\begin{array}{l}\text { Satisfying industry } \\
\text { needs }\end{array}$ & $\begin{array}{l}\text { - Level of satisfaction of industry } \\
\text { needs by the results of R\&D } \\
\text { projects carried out through the } \\
\text { IRC }\end{array}$ & $\begin{array}{l}\text { 1-Very dissatisfied, } \\
\text { 2-Dissatisfied } \\
\text { 3-Unsure, 4- } \\
\text { Satisfied, 5-Very } \\
\text { satisfied }\end{array}$ & $0.80(0.42)$ & Very good \\
\hline & & $\begin{array}{l}\text { Expansion of the } \\
\text { research program }\end{array}$ & $\begin{array}{l}\text { - Level of increase in the research } \\
\text { themes by working with } \\
\text { industrial partners of the IRC on } \\
\text { R\&D projects }\end{array}$ & $\begin{array}{l}\text { 1-Very low, 2-Low. } \\
\text { 3-Medium, } \\
\text { 4-High, 5-Very high }\end{array}$ & $0.30(0.48)$ & Fair \\
\hline
\end{tabular}




\begin{tabular}{|c|c|c|c|c|c|c|}
\hline Component & $\begin{array}{l}\text { Class of } \\
\text { Outcomes }\end{array}$ & Outcome Criterion & Metric & Scale & $\begin{array}{c}\text { Mean } \\
\text { (Standard } \\
\text { Deviation) for } \\
\text { each Criterion }\end{array}$ & $\begin{array}{c}\text { Interpretation } \\
\text { of Composite } \\
\text { Index }\end{array}$ \\
\hline & $\begin{array}{l}\text { Long-term } \\
\text { outcomes }\end{array}$ & $\begin{array}{l}\text { Enhancing Canada's } \\
\text { level of technological } \\
\text { innovation on a } \\
\text { global scale }\end{array}$ & $\begin{array}{l}\text { - Level of effect of the different } \\
\text { research themes within the IRC } \\
\text { on the enhancement of } \\
\text { Canada's level of technological } \\
\text { innovation on a global scale }\end{array}$ & $\begin{array}{l}\text { 1- Not effective at } \\
\text { all, 2- Slightly } \\
\text { effective, 3- } \\
\text { Somewhat effective, } \\
\text { 4- Very effective, 5- } \\
\text { Extremely effective }\end{array}$ & $0.47(0.28)$ & Good \\
\hline
\end{tabular}

Note: The last column shows the descriptive statistics of the normalized composite indices of each criterion, on a scale of 0 to 1 , which were determined based on the respondents' evaluations of the metrics for the criteria. 


\section{Figure Captions}

Figure 1. Components of the Logic Model Representing the University's Role in the R\&D Partnership

Figure 2. Components of the Logic Model Representing the Industry's Role in the R\&D Partnership

Figure 3. Components of the Logic Model Representing the Government's Role in the R\&D Partnership

Figure 4. Simplified Relationships Among the Components of the Validated Logic Model 


\section{Tables}

Table 1. Examples of Inputs and Outputs Criteria and Corresponding Metrics for the University Party

\begin{tabular}{|c|c|c|c|c|c|}
\hline Component & Criterion & Metric & Scale & $\begin{array}{l}\text { Mean (Standard } \\
\text { Deviation) for each } \\
\text { Criterion }\end{array}$ & $\begin{array}{l}\text { Interpretation } \\
\text { of Composite } \\
\text { Index }\end{array}$ \\
\hline \multirow[t]{3}{*}{ Inputs } & $\begin{array}{l}\text { Previous R\&D } \\
\text { achievements }\end{array}$ & $\begin{array}{l}\text { - Number of R\&D projects with industry } \\
\text { participants of the IRC completed on time and } \\
\text { on budget over the past } 5 \text { years }\end{array}$ & Numerical values & \multirow[t]{2}{*}{$0.43(0.23)$} & \multirow[t]{2}{*}{ Good } \\
\hline & & $\begin{array}{l}\text { - Total number of R\&D projects with industry } \\
\text { participants of the IRC over the past } 5 \text { years }\end{array}$ & Numerical values & & \\
\hline & & $\begin{array}{l}\text { - Quality of laboratories and/ or research spaces } \\
\text { used in R\&D projects within the IRC }\end{array}$ & $\begin{array}{l}\text { 1-Poor, 2-Fair, 3-Good, } \\
\text { 4-Very good, 5-Excellent }\end{array}$ & $0.32(0.21)$ & Fair \\
\hline \multirow[t]{5}{*}{ Outputs } & $\begin{array}{l}\text { Doing research in } \\
\text { collaborative } R \& D \\
\text { teams }\end{array}$ & $\begin{array}{l}\text { - Frequency of doing research in collaboration } \\
\text { with industrial partners of the IRC }\end{array}$ & $\begin{array}{l}\text { 1-Never, 2-Rarely, } \\
\text { 3-Sometimes, 4-Often, } \\
\text { 5-Usually }\end{array}$ & \multirow[t]{5}{*}{$0.52(0.14)$} & \multirow[t]{5}{*}{ Good } \\
\hline & & $\begin{array}{l}\text { - Time spent in years by graduate students (i.e., } \\
\text { doctorate and master's students) to complete } \\
\text { their degrees within the IRC }\end{array}$ & Numerical values & & \\
\hline & & $\begin{array}{l}\text { - Number of graduate students posted at } \\
\text { industrial partners' organization and/or job sites } \\
\text { within the IRC over the past } 5 \text { years }\end{array}$ & Numerical values & & \\
\hline & & $\begin{array}{l}\text { - Number of basic, applied, and basic and applied } \\
\text { R\&D projects carried out within the IRC over } \\
\text { the past } 5 \text { years }\end{array}$ & Numerical values & & \\
\hline & & $\begin{array}{l}\text { - Level of satisfaction with the collaboration on } \\
\text { R\&D projects within the IRC }\end{array}$ & $\begin{array}{l}\text { 1-Very dissatisfied, } \\
\text { 2-Dissatisfied, 3-Unsure, } \\
\text { 4-Satisfied, 5-Very satisfiec }\end{array}$ & & \\
\hline
\end{tabular}




\begin{tabular}{|c|c|c|c|c|c|}
\hline Component & Criterion & Metric & Scale & $\begin{array}{c}\text { Mean (Standard } \\
\text { Deviation) for each } \\
\text { Criterion }\end{array}$ & $\begin{array}{c}\text { Interpretation } \\
\text { of Composite } \\
\text { Index }\end{array}$ \\
\hline & $\begin{array}{l}\text { Developing tools and } \\
\text { solutions to problems } \\
\text { through R\&D } \\
\text { projects }\end{array}$ & $\begin{array}{l}\text { - Frequency of implementing tools and solutions } \\
\text { developed through R\&D projects by the } \\
\text { industrial partners of the IRC }\end{array}$ & $\begin{array}{l}\text { 1-Never, 2-Rarely, } \\
\text { 3-Sometimes, 4-Often, } \\
\text { 5-Usually }\end{array}$ & \multirow[t]{3}{*}{$0.70(0.23)$} & \multirow[t]{3}{*}{ Very good } \\
\hline & & $\begin{array}{l}\text { - Number of software applications developed } \\
\text { through R\&D projects within the IRC over the } \\
\text { past } 5 \text { years }\end{array}$ & Numerical values & & \\
\hline & & $\begin{array}{l}\text { - Level of quality of R\&D projects results within } \\
\text { the IRC }\end{array}$ & $\begin{array}{l}\text { 1-Poor, 2-Fair, 3-Good, } \\
\text { 4-Very good, 5-Excellent }\end{array}$ & & \\
\hline
\end{tabular}

Note: The last column shows the descriptive statistics of the normalized composite indices of each criterion, on a scale of 0 to 1 , which were determined based on the respondents' evaluations of the metrics for the criteria. 
Table 2. Examples of Outcomes Criteria and Corresponding Metrics for the University Party

\begin{tabular}{|c|c|c|c|c|c|c|}
\hline Component & $\begin{array}{l}\text { Class of } \\
\text { Outcomes }\end{array}$ & Outcome Criterion & Metric & Scale & $\begin{array}{c}\text { Mean } \\
\text { (Standard } \\
\text { Deviation) for each } \\
\text { Criterion }\end{array}$ & $\begin{array}{l}\text { Interpretation } \\
\text { of Composite } \\
\text { Index }\end{array}$ \\
\hline \multirow[t]{2}{*}{ Outcomes } & $\begin{array}{c}\text { Medium-term } \\
\text { outcomes }\end{array}$ & $\begin{array}{l}\text { Satisfying industry } \\
\text { needs }\end{array}$ & $\begin{array}{l}\text { - Level of satisfaction of industry } \\
\text { needs by the results of R\&D } \\
\text { projects carried out through the } \\
\text { IRC }\end{array}$ & $\begin{array}{l}\text { 1-Very dissatisfied, 2- } \\
\text { Dissatisfied } \\
\text { 3-Unsure, 4-Satisfied, } \\
\text { 5-Very satisfied }\end{array}$ & $0.80(0.42)$ & Very good \\
\hline & $\begin{array}{l}\text { Long-term } \\
\text { outcomes }\end{array}$ & $\begin{array}{l}\text { Enhancing Canada's } \\
\text { level of technological } \\
\text { innovation on a global } \\
\text { scale }\end{array}$ & $\begin{array}{l}\text { - Level of effect of the different } \\
\text { research themes within the IRC on } \\
\text { the enhancement of Canada's level } \\
\text { of technological innovation on a } \\
\text { global scale }\end{array}$ & $\begin{array}{l}\text { 1- Not effective at all, } \\
\text { 2- Slightly effective, } \\
\text { 3- Somewhat } \\
\text { effective, } 4 \text { - Very } \\
\text { effective, 5- Extremely } \\
\text { effective }\end{array}$ & $0.47(0.28)$ & Good \\
\hline
\end{tabular}

Note: The last column shows the descriptive statistics of the normalized composite indices of each criterion, on a scale of 0 to 1 , which were determined based on the respondents' evaluations of the metrics for the criteria. 


\begin{tabular}{|c|c|c|}
\hline Inputs & Outputs & Outcomes-Impact \\
\hline Resources & Activities & Medium-term $\longrightarrow$ Long-term/Impact \\
\hline $\begin{array}{l}\text { Qualified research team } \\
\text { involved in R\&D projects } \\
\text { Laboratories and facilities } \\
\text { involved in R\&D projects } \\
\text { Industry connections } \\
\text { facilitated by R\&D } \\
\text { collaborations } \\
\text { Funding } \\
\text { Trust in industrial partners } \\
\text { working on R\&D projects } \\
\text { Time spent on R\&D } \\
\text { projects } \\
\text { Previous R\&D } \\
\text { achievements } \\
\text { Teamwork effectiveness in } \\
\text { R\&D collaborations }\end{array}$ & $\begin{array}{l}\text { Doing research in collaborative } \\
\text { R\&D teams } \\
\text { Developing tools and solutions to } \\
\text { problems through R\&D projects } \\
\text { Training industry professionals to } \\
\text { enhance their performance and } \\
\text { knowledge } \\
\text { Publishing papers, technical reports, } \\
\text { newsletters, books, and } \\
\text { manuals/guides } \\
\text { Introducing presentations and } \\
\text { posters at conferences and seminars } \\
\text { Communicating R\&D progress and } \\
\text { results through the university } \\
\text { research team's website } \\
\text { Organizing workshops to present the } \\
\text { results of R\&D projects } \\
\text { Participating in advisory committee } \\
\text { meetings }\end{array}$ & $\begin{array}{l}\text { Short-term outcomes: Graduating highly experienced personnel, Better } \\
\text { understanding of industry needs, Linking scientific theories with practical } \\
\text { applications, Increased university research capacity, Increasing the } \\
\text { knowledge of researchers, Fostering improved collaboration and stable } \\
\text { relationships with industry, Enhanced networks/partnerships (universities } \\
\text { and industrial partners), Enhanced collaborations and interaction between } \\
\text { the university research team's leader and other university colleagues, } \\
\text { Improving the reputation of researchers among their peers, Improved } \\
\text { research quality of the university research team, Improved industrial } \\
\text { relevance of research, Better development in the research facilities, and } \\
\text { Better development in the infrastructure. } \\
\text { Medium-term outcomes: Satisfying industry needs, Creation of innovative } \\
\text { technologies, Spin outs, Enhanced academic reputation of the department } \\
\text { and/or university, Enhanced feedback mechanisms for better } \\
\text { communication and collaboration with industry, Expansion of the research } \\
\text { program, Enhancement of the management system for R\&D projects, and } \\
\text { Employment of highly qualified personnel (HQP) (i.e., Undergraduate } \\
\text { Students, Masters Students, Doctoral Students, Postdoctoral Fellows, } \\
\text { Research Associates, Technical Writers, and Programmers). } \\
\text { Long-term outcomes: Maintaining a leading position among top-ranked } \\
\text { research universities all over the world, Development of nationally and } \\
\text { internationally-recognized expertise in various research areas, Enhancing } \\
\text { Canada's level of technological innovation on a global scale, Enhancing the } \\
\text { global competitiveness of the Canadian economy, Contributing to improved } \\
\text { economic and social conditions for Canadians, and Contributing to } \\
\text { improved environmental conditions for Canadians. }\end{array}$ \\
\hline
\end{tabular}




\begin{tabular}{|c|c|c|}
\hline Inputs & Outputs & Outcomes-Impact \\
\hline Resources & Activities & Short-term $\longrightarrow$ Medium-term $\longrightarrow$ Long-term/Impact \\
\hline $\begin{array}{l}\text { Organizational funding for } \\
\text { R\&D projects } \\
\text { In-kind contributions } \\
\text { supplied by the organization } \\
\text { to the university } \\
\text { Qualified industry } \\
\text { professionals involved in } \\
\text { R\&D projects } \\
\text { Time spent on R\&D } \\
\text { projects } \\
\text { Previous successful } \\
\text { collaborative R\&D projects } \\
\text { Trust in academic partners } \\
\text { working on R\&D projects } \\
\text { Teamwork effectiveness in } \\
\text { R\&D collaborations } \\
\text { Access to technical data } \\
\text { provided to the university } \\
\text { research team } \\
\text { University connections } \\
\text { facilitated by R\&D }\end{array}$ & $\begin{array}{l}\text { Working with the university in the } \\
\text { execution of R\&D projects } \\
\text { Assisting the university in the } \\
\text { development of tools to address } \\
\text { market needs } \\
\text { Providing industry training to } \\
\text { graduate students by offering } \\
\text { internships at the organization } \\
\text { Providing technical support to the } \\
\text { university research team on R\&D } \\
\text { projects } \\
\text { Using university facilities and } \\
\text { laboratories for the purpose of } R \& D \\
\text { projects } \\
\text { Participating in advisory committee } \\
\text { meetings }\end{array}$ & $\begin{array}{l}\text { Short-term outcomes: Fostering improved collaboration with the } \\
\text { university on R\&D projects, Increasing the experience of employees, } \\
\text { Increasing the knowledge of employees, Improving the organization's } \\
\text { national competitive position among other organizations, Improved research } \\
\text { quality of the university research team, Improved industrial relevance of } \\
\text { research, and Better understanding of market needs. } \\
\text { Medium-term outcomes: Hiring highly qualified personnel (HQP) (i.e., } \\
\text { Undergraduate Students, Masters Students, Doctoral Students, Postdoctoral } \\
\text { Fellows, Research Associates, Technical Writers, and Programmers) to } \\
\text { work at the organization, Enhanced feedback mechanisms for better } \\
\text { communication and collaboration with the university on R\&D projects, } \\
\text { Changes in the organization's practices and strategies leading to improved } \\
\text { industry performance, Sharing in the ownership of innovative results and } \\
\text { products developed through R\&D partnerships, and Enhancement of the } \\
\text { management system for construction projects. } \\
\text { Long-term outcomes: Higher profits for the organization and better project } \\
\text { and organizational performance, Increased competitive standing of the } \\
\text { organization in international markets, Contributing to improved economic } \\
\text { and social conditions for Canadians, Enhancing the global competitiveness } \\
\text { of the Canadian economy, Contributing to improved environmental } \\
\text { conditions for Canadians, and Enhancing the organization's level of } \\
\text { innovation. }\end{array}$ \\
\hline
\end{tabular}




\begin{tabular}{|c|c|c|}
\hline Inputs & Outputs & Outcomes-Impact \\
\hline Resources & Activities & Short-term $\longrightarrow$ Medium-term $\longrightarrow$ Long-term/Impact \\
\hline $\begin{array}{l}\text { Qualified personnel } \\
\text { involved in R\&D } \\
\text { partnerships } \\
\text { Funding of different R\&D } \\
\text { partnerships } \\
\text { Time spent on R\&D } \\
\text { projects } \\
\text { Previous R\&D } \\
\text { achievements } \\
\text { Existing management tools } \\
\text { and systems } \\
\text { Existing partnerships } \\
\text { Knowledge of market and } \\
\text { government needs }\end{array}$ & $\begin{array}{l}\text { Linking industry with university } \\
\text { through R\&D collaborations } \\
\text { Attracting highly qualified } \\
\text { personnel (HQP) (i.e., Masters } \\
\text { Students, and Doctoral Students) to } \\
\text { work on different R\&D projects } \\
\text { Publishing of communication } \\
\text { materials (i.e. guides, reports, } \\
\text { announcements, etc.) } \\
\text { Updating information on the website } \\
\text { of the funding agency } \\
\text { Review and selection of applications } \\
\text { for funding } \\
\text { Administration and management of } \\
\text { grants and the renewal process } \\
\text { Evaluation of progress reports from } \\
\text { the leaders of university research } \\
\text { teams } \\
\text { Providing feedback on progress } \\
\text { reports from the leaders of } \\
\text { university research teams } \\
\text { Providing training workshops for } \\
\text { university and industry groups }\end{array}$ & $\begin{array}{l}\text { Short-term outcomes: Improved research quality of the university research } \\
\text { teams' leaders, Improved research quality of the university research team, } \\
\text { Improved industrial relevance of research, Improved knowledge and } \\
\text { technologies in the relevant industrial area, Increased pool of highly } \\
\text { qualified personnel (HQP) (i.e., Undergraduate Students, Masters Students, } \\
\text { Doctoral Students, Postdoctoral Fellows, Research Associates, Technical } \\
\text { Writers, and Programmers) with research expertise relevant to the industrial } \\
\text { sector, Enhanced networks/ partnerships (universities and industry partners), } \\
\text { Enhanced collaborations and interaction between the university research } \\
\text { team's leader and other university colleagues, and Increased university } \\
\text { research capacity. } \\
\text { Medium-term outcomes: Enhanced use of research results by industrial } \\
\text { partners (i.e., new and/ or improved products and processes, policy } \\
\text { development, etc.), Transfer of knowledge and technologies to Canadian } \\
\text { companies and government groups, Increase in evidence-based regulations } \\
\text { and management practices, and Highly qualified personnel (HQP) (i.e., } \\
\text { Undergraduate Students, Masters Students, Doctoral Students, Postdoctoral } \\
\text { Fellows, Research Associates, Technical Writers, and Programmers) obtain } \\
\text { employment in their field of study and require less training once employed. } \\
\text { Long-term outcomes: Increased investment in R\&D partnerships by the } \\
\text { industrial sector, Stronger Canadian economy, Enhanced economic and } \\
\text { social benefits for Canadians, Increased employment opportunities for } \\
\text { highly qualified personnel (HQP) (i.e., Undergraduate Students, Masters } \\
\text { Students, Doctoral Students, Postdoctoral Fellows, Research Associates, } \\
\text { Technical Writer, and Programmers) in Natural Sciences and Engineering } \\
\text { (NSE), Improved R\&D performance by the Canadian construction industry, } \\
\text { and Contributing to improved environmental conditions for Canadians. }\end{array}$ \\
\hline
\end{tabular}




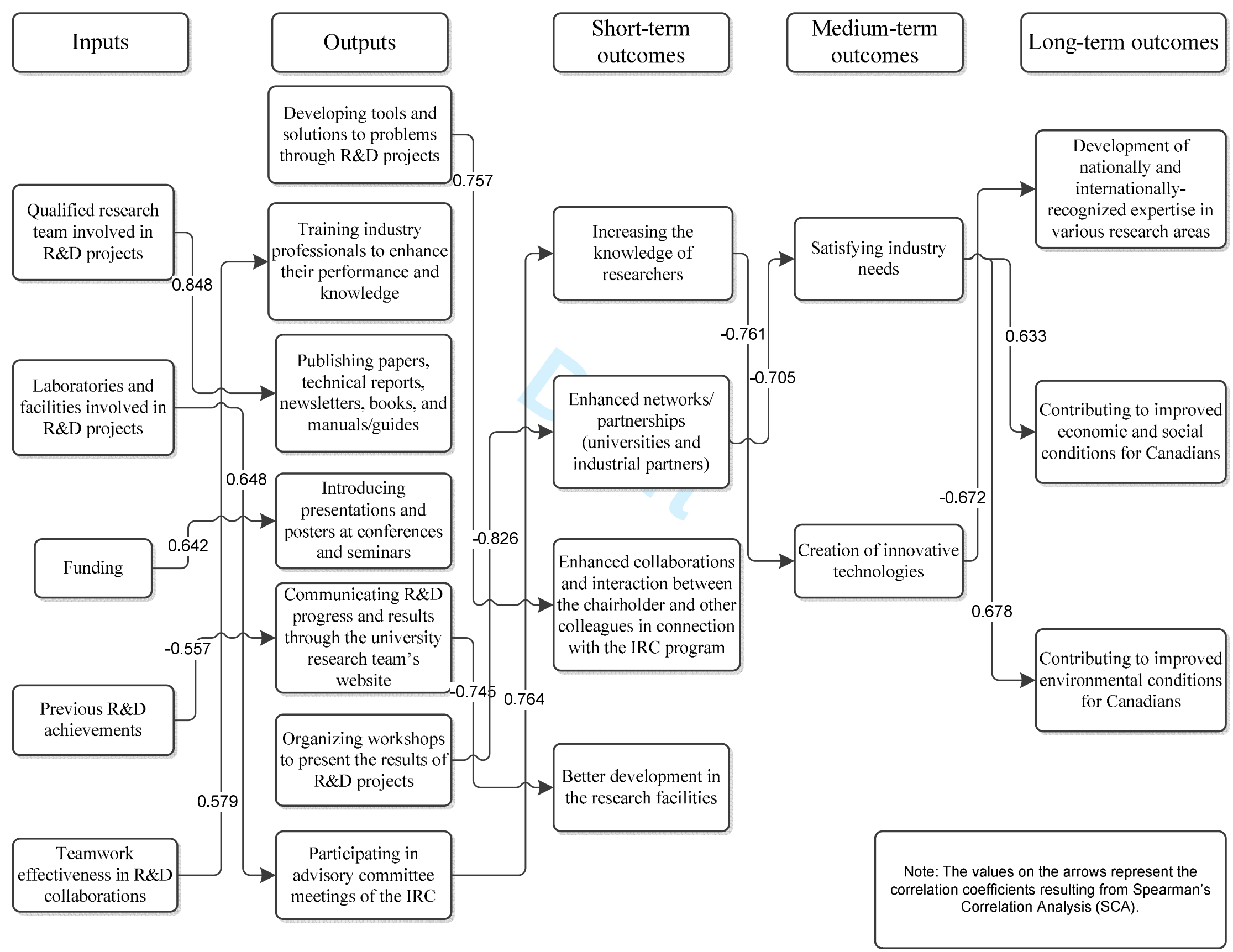

https://mc06.manuscriptcentral.com/cjce-pubs 